\title{
Application of fractal properties in studies of financial markets
}

\author{
Sergey Erokhin ${ }^{1, *}$ and Olga Roshka ${ }^{1}$ \\ ${ }^{1}$ Moscow State University of Civil Engineering, Yaroslavskoe shosse, 26, Moscow, 129337, Russia
}

\begin{abstract}
When studying the financial markets, the currency quotations of the Russian ruble/US dollar pair are examined for fractality. It is demonstrated that the time series of the quotations under study has basic fractal properties. Hurst exponent is used here to confirm the hypothesis of fractality whereby Hausdorff dimension was calculated, which turned out to be a fraction. The state of flux graphs were compared with the solution graphs of the known fractional differential equation of a point particle random walk along a self-similar fractal set. The solution of such an equation is given using the Mittag-Leffler functions. The graphs of these solutions are compared with state of flux graphs for different time intervals. Hence, it is proved that the Russian financial market is fractal and these results will help to forecast market behavior for a specified time interval in the future.
\end{abstract}

\section{Introduction}

Today a large number of different mathematical models are known to describe market behavior. Undoubtedly, each of them has its own merits, but all of them are united by the fact that probably none is able to describe exactly the complex dynamics of some financial time series that have different irregular run-outs.

These run-outs correspond to different events, such as the economic crisis, seasonal fluctuations, breakdowns, takeoffs, etc. [1-5].

Fractal is an object possessing the property of self-similarity, irregularity, and fractal. $[6,7]$. Self-similarity means that studied object does not have the typical scale. All fractals that have at least some symmetry are self-similar. In turn, this means that many of their structural fragments in sum are strictly repeated through certain intervals in space. These objects are very different in nature, and their appearance and form remain intact regardless of the scale at which they are viewed.

With respect to financial markets $[8,9]$, self-similarity means that the formation of the same typical forms should occur at variable amounts in time. The one-minute graph should describe the fractal structure as well as the monthly one, and the monthly one in turn, just like the annual one, etc. If you compress the time scale by a factor of $h$, and the $\mathrm{Y}$-axis - by a factor of $\mathrm{h}^{\wedge} \mathrm{H}$, then histograms of returns will be observationally equivalent.

\footnotetext{
* Corresponding author: ErokhinSV@mgsu.ru
} 


\section{Fractal properties of financial markets}

Let us consider in more detail an example of fractal properties in a common foreign exchange market. The first property is scalability. It is easy to see that graphs are similar, although they have a different time scale. Fig. 1 shows a scale by minute, fig. 2 - by week.

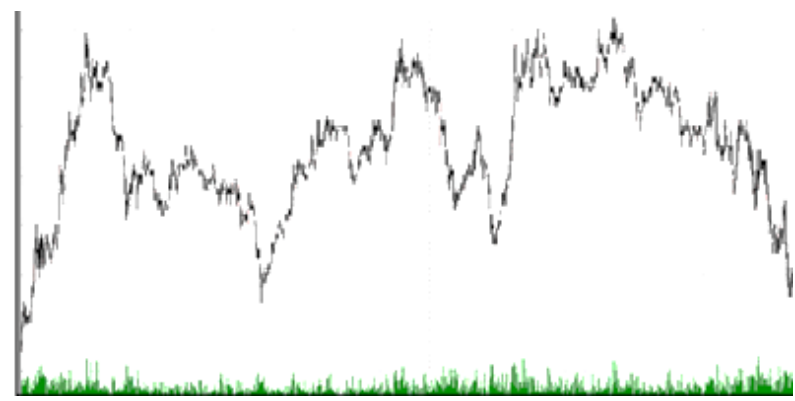

Fig. 1. The scale of prices by the minute (U.S. Dollar/Yen)

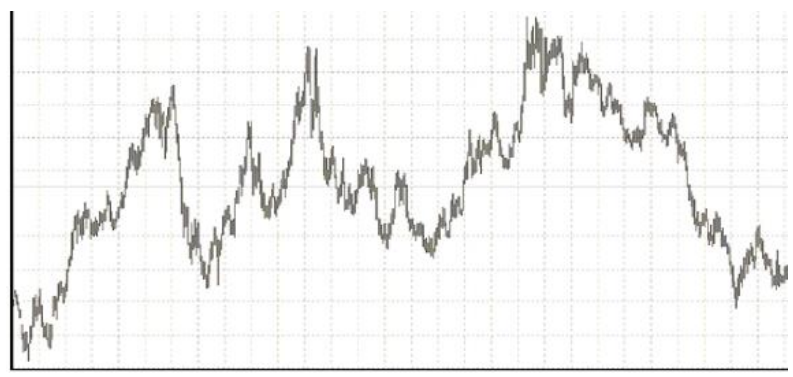

Fig. 2. The scale of prices by week (Euro/U.S. Dollar)

The next property of fractals is their irregularity. Fractals are described by irregular functions. It is known from the course of analysis that such a function is nowhere differentiable, and the graph is not continuously differentiable at any point (saw-toothed). As we see, this has direct relation to the market. Hence, it is obvious that prices are extremely fluctuating and erratic, so most people think of complete chaos in the markets (fig. 3, 4).

Fractals have a fractional metric dimension. The fractional dimension is an indicator of the curve complexity. In the currency market, the dimension can be characterized by the state of flux of price quotations.

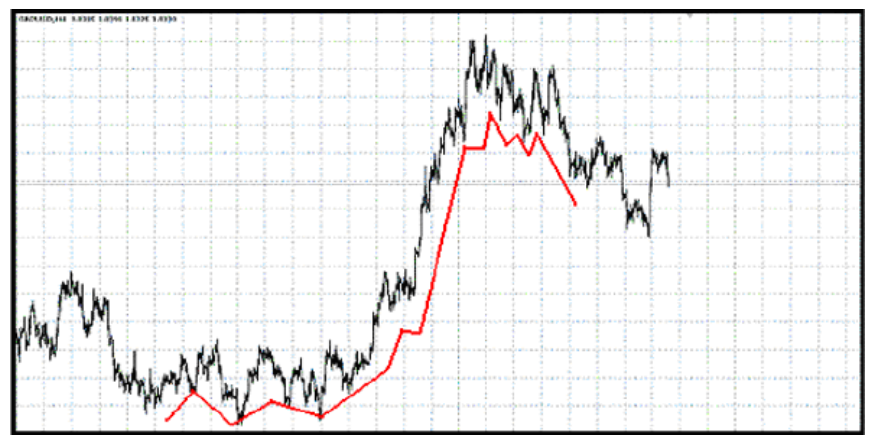

Fig. 3. State of flux of prices by the minute (U.S. Dollar/Yen) 


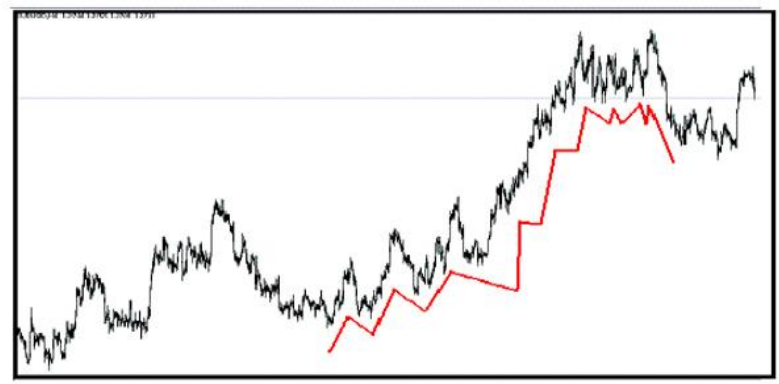

Fig. 4. State of flux of prices by week (Euro/U. S. Dollar)

\section{Fractal analysis of financial markets}

\subsection{Hurst exponent}

So, for further analysis, the indexes closing prices are used. This data is freely available on the Internet. In order to express the fractional dimension of any fractal, it is necessary to calculate such Hurst exponent. The Hurst exponent [10-12] is closely related to the Hausdorff dimension (expressed directly) by the relation

$$
D=2-H,
$$

where $\mathrm{D}$ is the Hausdorff dimension and $\mathrm{H}$ is the Hurst exponent.

In order to evaluate Hurst exponent first we analyzed exchange quotations of the MICEX index "Oil and Gas" in the time interval from 11.01.2005 to 05.12.2014 "in increments of" 1 day. The graph of closing price behavior, shown in the figure below, has a strong "irregularity", that is, we can assume that this time series is a fractal (fig. 5). The closing prices were taken, and Hurst exponent $\mathrm{H}=1.0215$ was calculated.

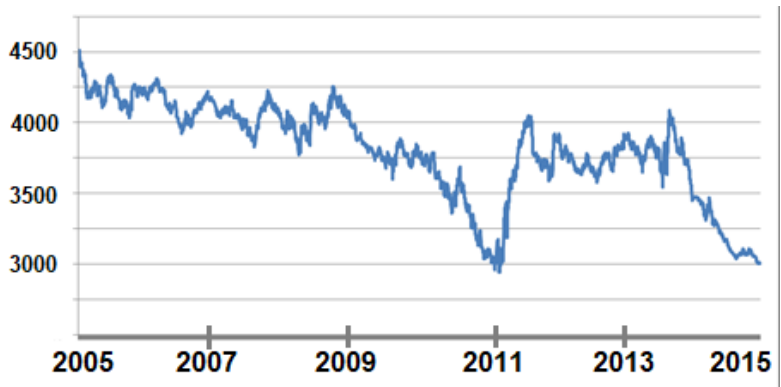

Fig. 5. The behavior graph of exchange quotations of the MICEX index "Oil and Gas" in the time interval from 11.01.2005 to 05.12.2014.

As you can see $0.5<H<1.5$. The case of $0.5<H<1.5$ is the most interesting. As we know, Hurst exponent, being in one of three intervals (pink, Brown and black noise, white noise is not considered because it is "uninteresting") can immediately characterize the process under study. Namely, in our case, the Hurst exponent just corresponds to the processes of "black noise", or noise with fractional dimension. These "noises" are observed in financial markets.

Let us consider the quotations of ruble/U.S. dollar pair for the period from 1999 to early 2015. The time series graph for this period is shown in Fig. 6. 


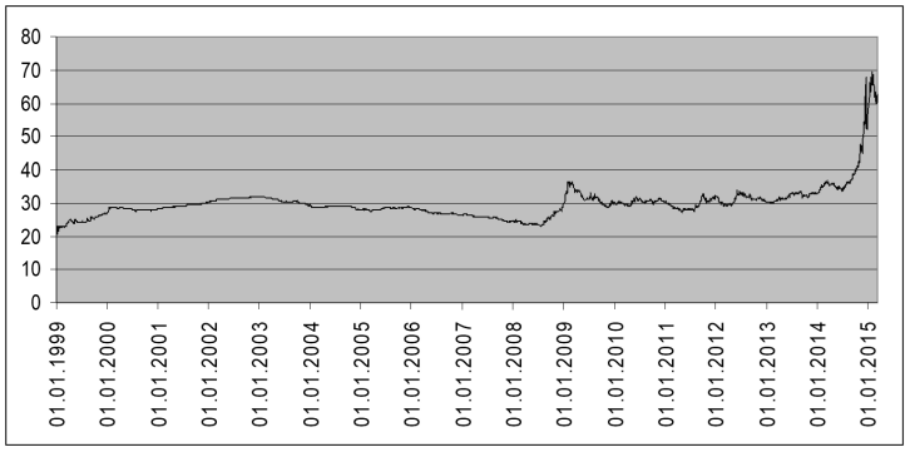

Fig. 6. The time series of ruble / U.S. dollar pair.

This series was tested for fractality using R/S analysis [13], calculation of the Hurst exponent $H$, which is a kind of "identifier" of studied structure fractality. The Hurst exponent is connected to the Hausdorff-Besikovitch dimensionality $D$ by the following relation: $D=$ $2-H$.

For this series, Hurst exponent turned out to be equal to 1.0212, and Hausdorff dimension is equal to 0.9788 . As we can see, the dimension turned out to be fractional, so in fact we can assume that this time series is a fractal.

\subsection{Fractal time series}

Fractal time series [14-16] are a whole class of fractal curves. Fractal curves are one of the important classes of self-similar and self-affinity sets. The most common examples of fractal curves are the Koch curve, the Peano curve, the Levy C curve [17]. A large class of continuous curves generated by the compression system $\left\{S_{1}, S_{2}, \ldots, S_{n}\right\}$ that address the following property:

- there is a set of points $\left(x_{1}, x_{2}, \ldots, x_{n}\right)$, such that

$\left\{S\left(x_{1}\right), S\left(x_{2}\right), \ldots, S\left(x_{n}\right)\right\}=\left\{x_{i-1}, x_{i}\right\}$ for all $i=\overline{1, n}$.

It should be noted that this property is addressed by any invariant set of the compression system, which is a Jordan curve (i.e., a continuous curve without self-intersections), for example, the Koch curve.

In addition, it has been known that if the alpha parameter of the Levy law is equal to two (or very close), then we get Gauss. However, the above alpha parameter in Matlab has a meaning of 1.3 , which confirms the suspicion that the quotations are distributed according to a stable law.

The analysis of the time series on Matlab using the Distribution Fitting Tool (Fig. 7) shows that the Levy's probability density function (stable distribution) in the best way approximates the time series of quotations:

1) Gauss distribution (blue line)

2) Lognorm distribution (orange line)

3) Levy distribution (red line)

4) Gauss returns (brown line)

5) Exponent distribution (pink line) 


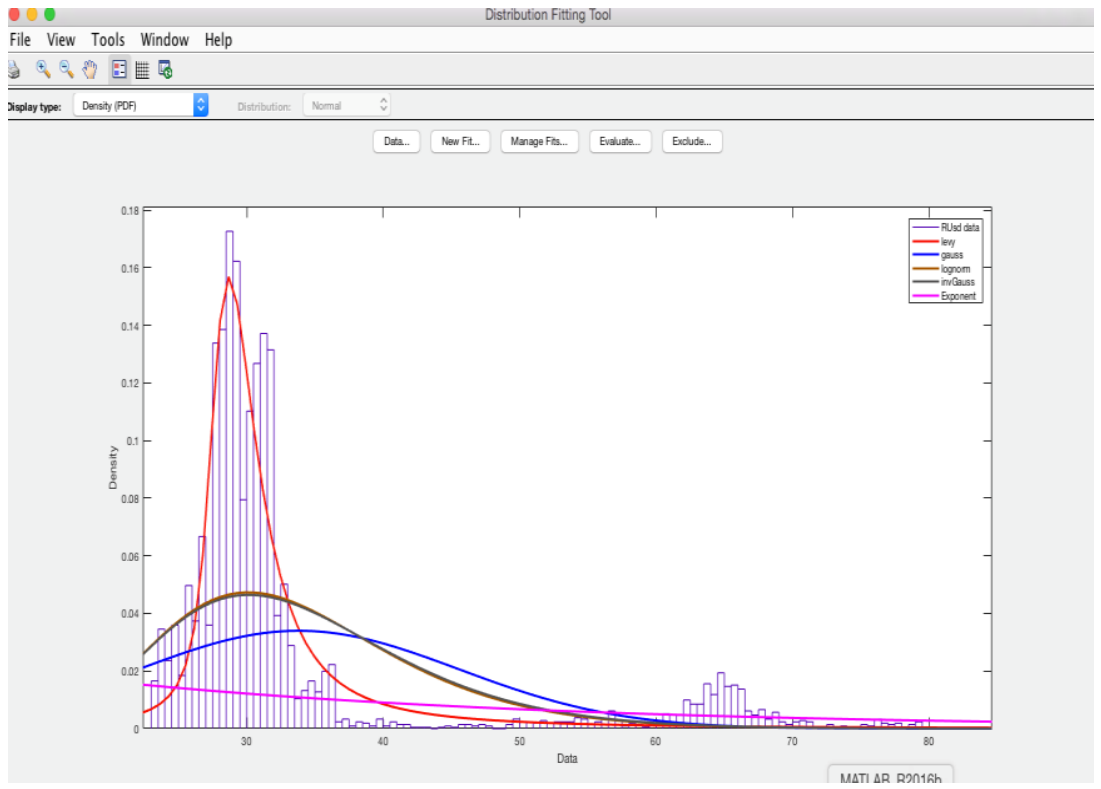

Fig. 7. Time-series analysis

The daily opening prices of the ruble/U.S. dollar quotations were studied for a full year 2016 (January-December). Approximation was carried out under various statistical laws. As may be inferred from the histogram, Levy's stable distribution gives the best suitable result. Choosing Levy as the best distribution approximating this series, we will analyze its parameters.

The Distribution Fitting Tool allows calculating these parameters. The following estimates have been obtained for our series (Fig. 8)

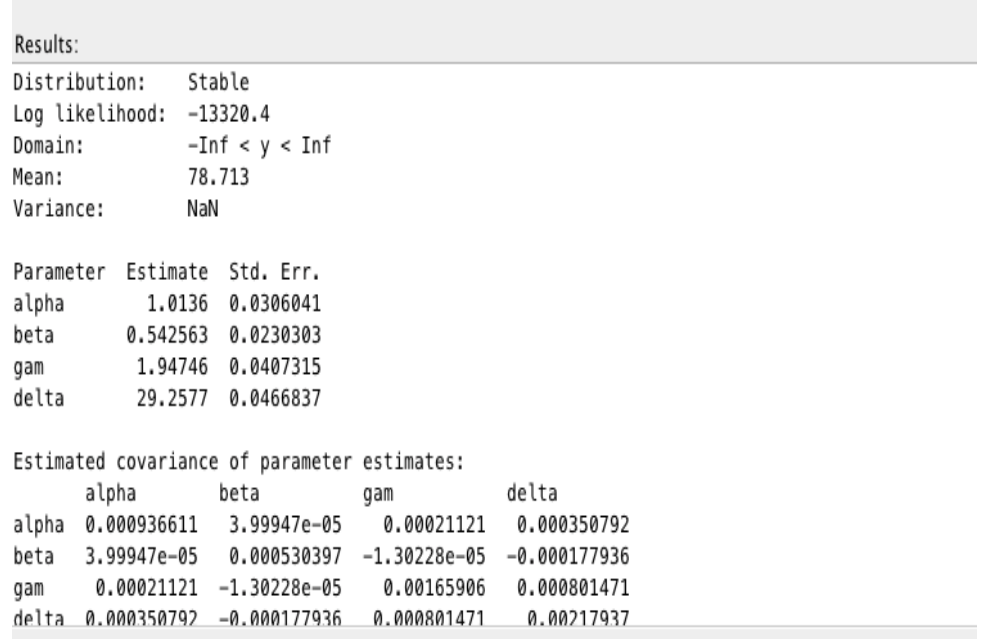

Fig. 8. Parameter estimates for a Levy's stable distribution.

Now we will analyze a number of logreturns, calculated by formula

$$
D=\ln \left(\frac{P_{i+1}}{P_{i}}\right)
$$


Figure 9 shows the distribution graphs - stable (red line) and Gauss (blue line), as well as a histogram of logreturns.

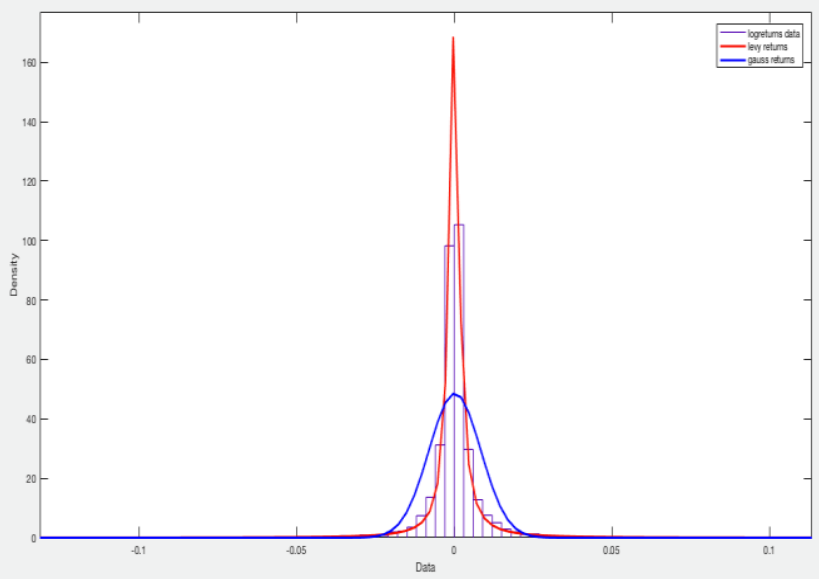

Fig. 9. Studied distributions graphs

Results screen shot of calculations of parameters for Levy's stable distribution is given below (Fig. 10).

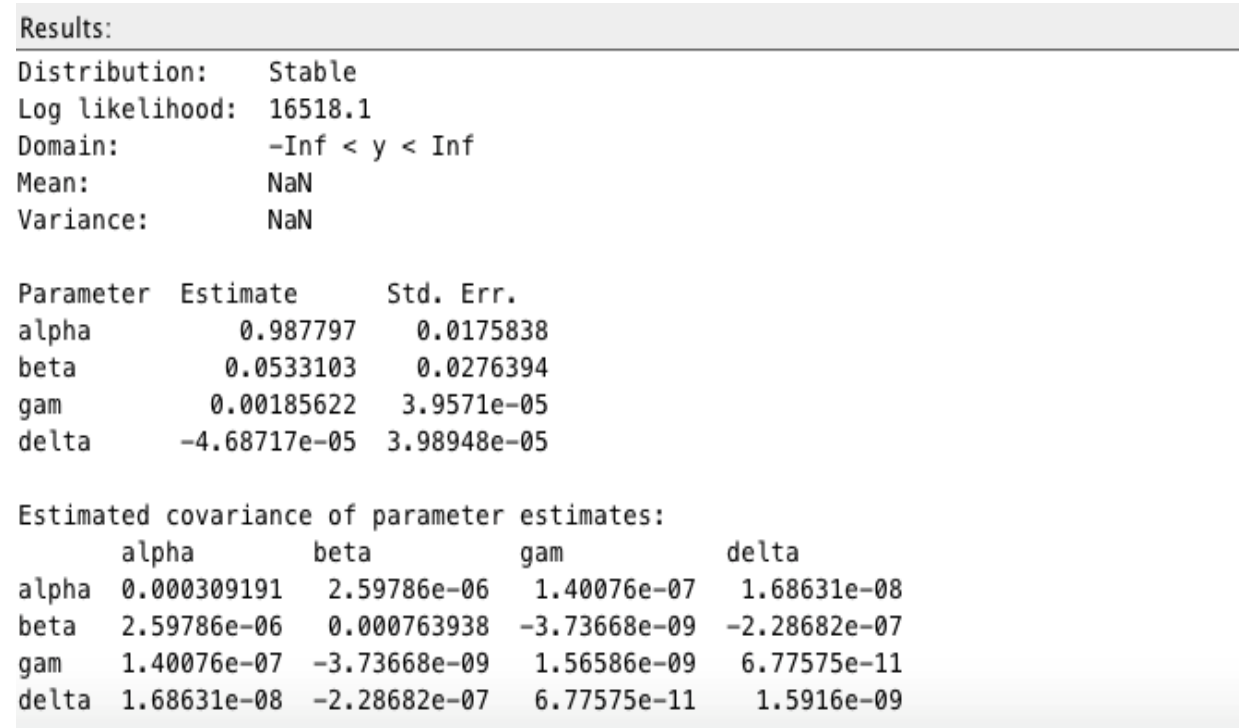

Fig. 10. Parameter estimates for a Levy's stable distribution.

It can also be noted that the state of flux distribution for a given period from 2000 to 2016 is also according to the law of Levy. Thus, we get the distribution of currency quotations according to the Levy stable law. 


\section{Conclusions}

The paper shows that the Russian financial market has fractal properties. Hurst exponent and Hausdorff dimension which is fractal were calculated by means of fractal analysis for market studying. Fractal analysis is a valuable tool for working with the Russian currency market, and the results can be used to forecast the behavior of the market at a predetermined time interval in the future.

\section{References}

1. A. Almazov. Fraktal'naya teoriya. Kak pomenyat' vzglyad na rynki (Admiral Markets, 2009)

2. J. Korbel, Yu. Luchko. Fr. Calc. and Appl. An. 19, 6 (2016)

3. S. Teplov $R / S$-analiz amerikanskogo fondovogo, rossiyskogo fondovogo $i$ valyutnogo rynkov (Finansovyy sektor v ekonomike, MFPA, 2007)

4. M. Butovskiy. Vestnik Buryatskogo gosudarstvennogo universiteta. 9: Matematika, informatika. pp. 237-244 (2011)

5. R. Kronover. Fraktaly i khaos v dinamicheskikh sistemakh. (Tekhnosfera, 2006)

6. B. Mandel'brot Fraktaly i khaos. Mnozhestvo Mandel'brota i drugie chudesa (NITs «Regulyarnaya i khaoticheskaya dinamika», 2009)

7. B. Mandel'brot Fraktaly, sluchay $i$ finansy. (NITs «Regulyarnaya i khaoticheskaya dinamika», 2004)

8. URL: http://dx.doi.org/10.1016/j.camwa.2016.06.038

9. I. Gnilomedov. Proc. Conf. Integrirovannye modeli, myagkie vychisleniya, veroyatnostnye sistemy i kompleksy programm v iskusstvennom intellekte (Fizmatlit, 2009)

10. I. Antonova, N. Chikina. Vestnik NTU "KhPI", 32, 1141 (2015)

11. Yu. Gromov. Fraktal'nyy analiz i protsessy v komp'yuternykh setyakh. (Izd-vo TGTU, 2007)

12. M. Dubovikov, A. Kryanev, N. Starchenko. Vestnik RUDN, 3(1), 81-95 (2004)

13. B. Kiselev. Voprosy geofiziki. 46, 446. (2013)

14. T. Barabash, A. Maslovskaya. Vestnik AmGU, 49, 31-38 (2010)

15. A. Loskutov. Analiz vremennykh ryadov. Kurs vremennykh ryadov. (MGU im. M.V. Lomonosova. 2009)

16. A. Lyubushin. Fraktal'nyy analiz vremennykh ryadov. (FGOBU VPO RGGU im. S. Ordzhonikidze, 2006)

17. D. Vinogradov. Radiofizika i radioastronomiya, 15(3) 338-347 (2010) 